\title{
Neurohypophysial dysmorphogenesis in mice lacking the homeobox gene Uncx4.1
}

\author{
C H J Asbreuk, J H van Doorninck, A Mansouri ${ }^{1}$, M P Smidt and J P H Burbach \\ Rudolf Magnus Institute of Neuroscience, Department of Pharmacology and Anatomy, University Medical Center Utrecht, Universiteitsweg 100 , 3584 CG Utrecht, \\ The Netherlands \\ ${ }^{1}$ Max Planck Institute for Biophysical Chemistry, Department of Molecular Cell Biology Am Fassberg 11, D37077 Göttingen, Germany
}

(Requests for offprints should be addressed to J P H Burbach; Email: j.p.h.burbach@med.uu.nl)

\begin{abstract}
A number of transcription factors have been implicated in the development of the hypothalamo-neurohypophysial system (HNS). Null mutations for these factors caused severe defects in proliferation, migration and survival during early embryogenesis. While they have informed about early events of HNS developments no insights in mechanisms of late development and maturation of this major peptidergic system have been obtained as yet. In a screen for adult-expressed homeobox genes we identified Uncx4.1 as a gene expressed in adult and embryonic magnocellular neurons of the (HNS). Null mutation of Uncx4.1 left these neurons viable and able to express neuropeptides. However, the connectivity of magnocellular neurons with posterior pituitary elements was compromised. As a consequence neuronal fibres traversed to the adenohypophysis. The penetrance of this phenotype was about $50 \%$. The data show a selective role of Uncx4.1 in controlling the development of connections of hypothalamic neurons to pituitary elements, allowing central neurons to reach the peripheral blood circulation and to deliver hormones for control of peripheral functions.
\end{abstract}

Journal of Molecular Endocrinology (2006) 36, 65-71

\section{Introduction}

The hypothalamo-neurohypophysis (HNS) consists of magnocellular neurons producing the peptide hormones vasopressin or oxytocin. The cell bodies are located in the paraventricular nucleus (PVN) and supraoptic nucleus $(\mathrm{SON})$ in the hypothalamus, and axons project to the neurohypophysis, where the hormones are secreted into the blood stream (Burbach et al. 2001). The early differentiation of these cell lineages has recently become much more comprehensible with the clarification of the role of transcription factors in (hypothalamic) development. Particularly, the Pit-Oct-Unc (POU) homeobox gene Brn2 (Nakai et al. 1995, Schonemann et al. 1995), the paired-type homeobox gene Otp (Acampora et al. 1999, Wang \& Lufkin 2000) and the basic helix-loop-helix (bHLH)-Per-Arnt-Sim (PAS) genes Siml (Michaud et al. 1998) and Arnt2 (Michaud et al. 2000) are essential for the proper anlage and development of peptidergic magnocellular neurons and other neurons of the neuroendocrine hypothalamus. Gene-deletion experiments showed that Otp is required for proliferation of progenitors and to maintain Brn2 expression, and for multiple stage-specific cellular functions leading to the establishment of the neuroendocrine hypothalamus. The POU homeobox gene Brn2 is essential for the development of cell types in the PVN and SON (Nakai et al. 1995, Schonemann et al. 1995). Deletion of Brn2 leads to a complete absence of the magnocellular neurons of the PVN and SON, and several parvocellular neurons, and consequently of neurons expressing vasopressin, oxytocin and corticotropin-releasing hormone. Otp-null mutant mice exhibit a phenotype similar to those lacking Brn2 (Acampora et al. 1999). In addition, they fail to develop the thyrotrophin-releasing hormone lineage and somatostatin-producing cells in the periventricular area and in the arcuate nucleus. Additional transcription factors implicated in development of the neuroendocrine hypothalamus are the cooperatively acting bHLH-PAS factors Siml and Arnt2. In a transcriptional cascade parallel to Otp, these factors are required for the maintenance of Brn2 expression. Mice lacking Sim1 or Arnt2 gradually lose Brn2 expression and the cell lineages depending on Brn2, thus resulting in a similar phenotype to the Brn2-null mutant (Michaud et al. 1998, 2000, Keith et al. 2001). In addition, periventricular somatostatin-producing neurons are missing.

In addition to cell survival, transcription factors involved in cellular differentiation in the central nervous system often influence the specification of axonal projections. Changes in cell fate that are seemingly without consequence during early development have been reported to alter axon projections, while leaving 
many other aspects of the cell intact (Sharma et al. 1998, Thor et al. 1999, Sharma \& Peng 2001). In this manner, coordinated expression of transcriptional activators and repressors defines neuronal connectivity (Winnier et al. 1999, Kania et al. 2000). Factors required for defining the connectivity and neuropeptide identity of the HNS during later stages of differentiation have not been identified yet. We identified a homeobox gene, Uncx $4 \cdot 1$, that is expressed in the HNS and provide here an analysis of hypothalamic neuroendocrine cells in the Uncx $4 \cdot 1$ mutant mouse. The results show that the magnocellular neurons in the PVN and SON are normal with respect to position and peptide identity, while some axonal projections fail to halt at the neural lobe of the pituitary gland. Instead, they project to the anterior lobe. The results indicate that Uncx $4 \cdot 1$ may have a role in defining pituitary neural lobe architecture during late development.

\section{Experimental procedures}

PCR fragments of 120 nucleotides containing homeobox sequences were generated by reverse transcriptase-PCR using degenerate primers based on homology between paired-type homeobox sequences (forward primer, 5'TGGTTYMRVAAYGGYHGMGGMARRTG-3'; reverse, 5'-GMRSCGMSAVMGSACMMBCTTYAC-3', according to van Schaick et al. 1997). cDNA prepared from total RNA of mouse ventral brain tissue was amplified and size-selected. A mini library was constructed in plasmid vector and clones were sequenced. The methods and conditions were those described by Asbreuk et al. (2002).

\section{Animals}

The Uncx4·1 mutant animals have been kept on a mixed background of $129 \times$ NMRI mice (Mansouri et al. 1997). Embryos were genotyped by PCR or genomic Southern blot analysis. DNA was isolated from the tails.

\section{In situ hybridization}

$\mathrm{CBA} \times \mathrm{C} 57 \mathrm{BL} 6$ mice were mated, and the morning when a vaginal plug was detected was considered embryonic day (E) $0 \cdot 5$. Pregnant mice were killed by cervical dislocation, and embryos were dissected and directly frozen in powdered dry-ice. For adult animals, the brain was dissected and frozen on powdered dry-ice. Digoxigenin-labelled sense and antisense RNA probes were generated according to the manufacturer's instructions (Roche Molecular Biochemicals). In situ hybridization with digoxigenin-labelled probes was performed essentially according to Jessell (http:// c.p.m.cnet.columbia.edu/dept/neurobeh/jessell/insitu. html; Schaeren-Wiemers \& Gerfin-Moser 1993). Briefly, hybridization was carried out at $72{ }^{\circ} \mathrm{C}$ in $50 \%$ formamide and $5 \times \mathrm{SSC}$. The digoxigenin was detected with an alkaline phosphatase-labelled antibody (Roche Molecular Biochemicals) using Nitro Blue Tetrazolium/ 5-bromo-4-chloroindol-3-yl phosphate as a substrate.

The following probes were used: a $700 \mathrm{bp}$ mouse Uncx $4 \cdot 1$ containing the homeobox domain (Mansouri et al. 1997) and full-length rat vasopressin cDNA were labelled with digoxigenin. Sense probes were used as controls and did not show any labelling. Counterstaining of histological sections was done with Cresyl Violet.

\section{Immunocytochemistry}

In double-labelling experiments, immunolabelling was performed following in situ hybridization. Alternatively, cryosections were fixed in 4\% paraformaldehyde. Sections were incubated with polyclonal anti-Otp (Lin et al. 1999) diluted $1: 500$ in $50 \mathrm{mM}$ Tris/0.5 M $\mathrm{NaCl} / 0 \cdot 5 \%$ Triton $\mathrm{X}-100$ or a polyclonal antiserum raised against the glycopeptide of the vasopressin precursor hormone (C3 final; van Leeuwen et al. 1989) diluted 1:5000, at $4{ }^{\circ} \mathrm{C}$ overnight. Sections were then incubated with biotinylated goat anti-rabbit (Vector Laboratories) secondary antibody, diluted 1:1000 in Tris-buffered saline, and processed according to the ABC method (Vector Laboratories). Digital images were made using a Zeiss 2 Axioscope microscope (Carl Zeiss Mikroskopie, Jena, Germany) equipped with an MCID system (Imaging Research, St. Catharines, Ontario, Canada).

\section{Results}

\section{Cloning and expression of Uncx4.1. in the hypothalamus}

One PCR product from degenerate reverse transcriptasePCR amplification of homeobox transcripts expressed in the ventral brain, which was not detected before in our screen of homeobox genes expressed in the adult brain (van Schaick et al. 1997, Smidt et al. 1997, Asbreuk et al. 2002), contained the homeobox of the Uncx $4 \cdot 1$. gene. Uncx $4 \cdot 1$ is a paired-type homeobox gene of which the homeodomain has closest similarity to that of the mouse homeobox genes Arx, Alx4, Cart-1, Ch $\times 10$, Vsx-1, Vsx-2, Phox2a and Phox2b, in order of similarity. It was originally identified by Rovescalli et al. (1996), and found to be expressed in the embryonic brain (Mansouri et al. 1997). We then used a 700 bp Uncx $4 \cdot 1$ mouse cDNA probe (Mansouri et al. 1997) to examine the expression of the Uncx $4 \cdot 1$. gene in the adult hypothalamus.

In situ hybridization showed that prominent fields of Uncx $4 \cdot 1$ expression were located in the magnocellular 


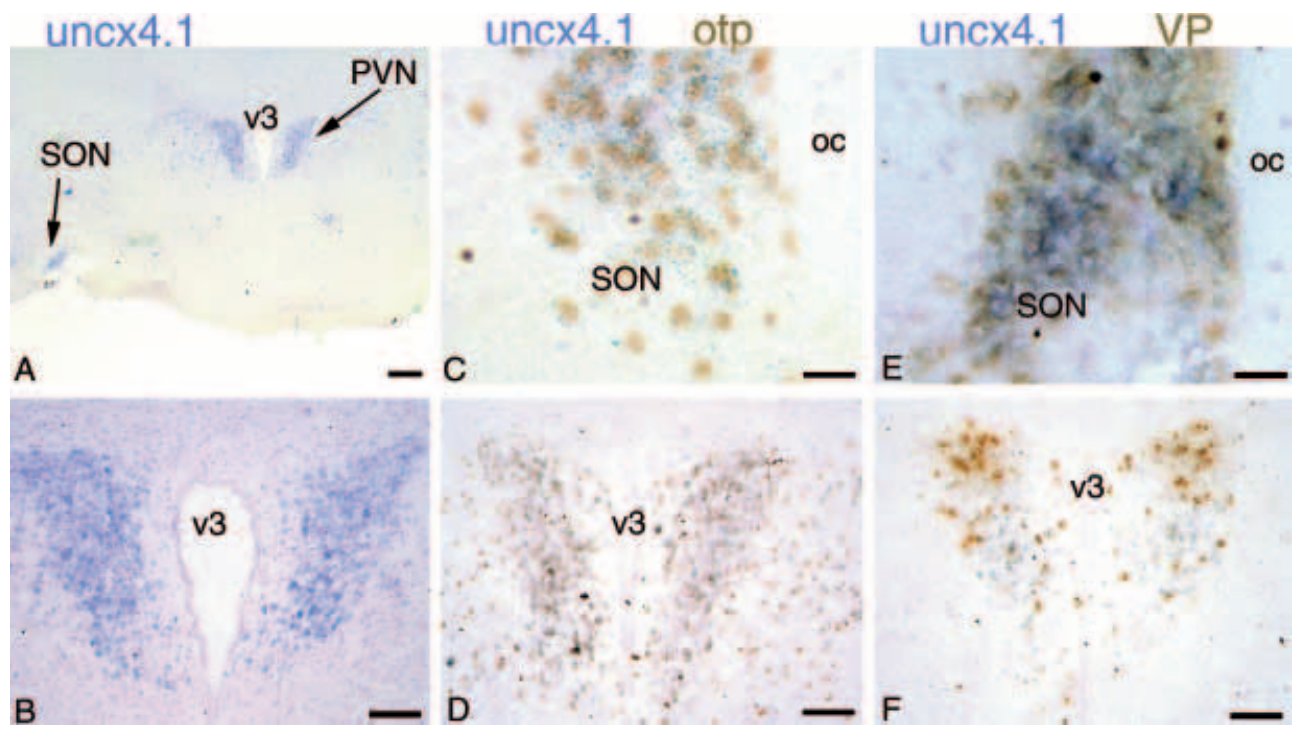

Figure 1 Expression of Uncx4.1 in the adult mouse hypothalamus. In situ hybridization for Uncx4.1 on coronal sections of adult mouse hypothalamus $(A, B)$. Panel B is an enlargement of the PVN field shown in panel A. Uncx4.1 in situ hybridization (blue) was combined with immunocytochemistry using an antibody recognizing Otp $(C, D)$ or the glycopeptide of the vasopressin precursor $(E, F)$. Uncx4.1 expression was detected in the PVN and SON $(A, B)$, overlapping with Otp $(C, D)$ and vasopressin $(E$, F). v3, third ventricle; oc, optic chiasm. Scale bars are $250 \mu \mathrm{m}(\mathrm{A}), 100 \mu \mathrm{m}(\mathrm{B}, \mathrm{D}, \mathrm{F})$ and $25 \mu \mathrm{m}(\mathrm{C}, \mathrm{E})$.

SON and PVN (Fig. 1A and B). Magnocellular neurons of the SON and PVN expressed Uncx4·1. Doublelabelling using a Uncx $4 \cdot 1$ in situ hybridization probe and an antiserum for immunocytochemistry of the C-terminal glycopeptide of the vasopressin precursor showed that Uncx $4 \cdot 1$ was expressed in vasopressin precursor neurons (Fig. 1E and F). Double-labelling with an antiserum for Otp confirmed the expression of Uncx $4 \cdot 1$ in all magnocellular neurons. The data also showed that Uncx $4 \cdot 1$ was more restricted in expression than Otp, which extends to multiple nuclei of the hypothalamus (Acampora et al. 1999; Fig. 1C and D).

\section{Uncx4.1 expression in the embryonic hypothalamo-neurohypophysial system}

In view of the role of homeobox genes as regulators of regional and cellular specification, we analysed brain expression of Uncx $4 \cdot 1$ during embryonic development of the mouse. At E12.5 Uncx4.1 was detected in the region becoming SON and PVN, known as supraoptic/ paraventricular area (Fig. 2A). Additional expression was detected in the preoptic area, the mamillary region and the zona limitans intrathalamica. The latter has been described previously (Mansouri et al. 1997). The target
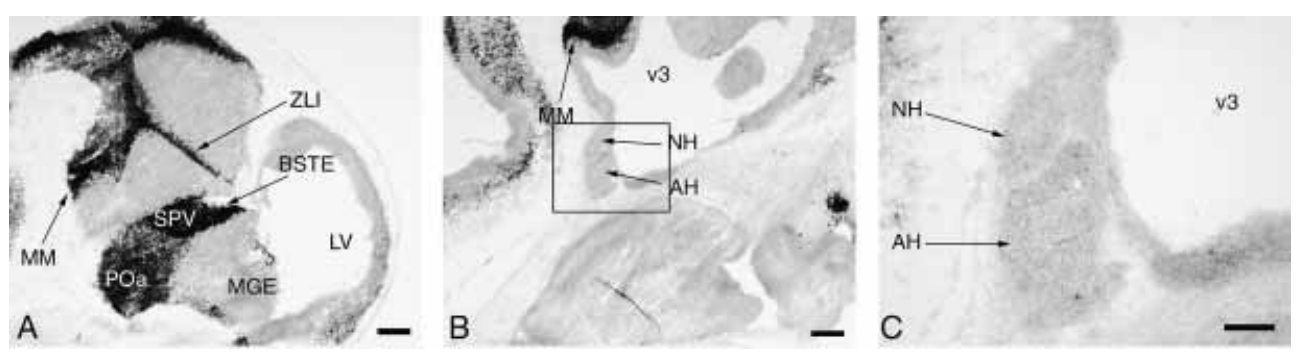

Figure 2 Brain expression of Uncx4.1 in the mouse embryo at E12.5. Uncx4.1 was detected in the embryonic supraoptic/paraventricular region (SPV) on sagittal sections. Additional expression was found in the bed nucleus of the stria terminalis (BSTE), preoptic area (POa), mamillary region (MM) and zona limitans intrathalamica (ZLI) $(A)$. In the pituitary gland no Uncx4.1 expression was detected $(B, C)$. The box in $B$ shows the area magnified in $C$. MGE, medial ganglionic eminence; LV, lateral ventricle; v3, third ventricle; $\mathrm{NH}$, neurohypophysis; $\mathrm{AH}$, adenohypophysis. Scale bars are $250 \mu \mathrm{m}(\mathrm{A}$, B) and $100 \mu \mathrm{m}(\mathrm{C})$. 
region of magnocellular fibre systems, the neurohypophysis, was devoid of Uncx $4 \cdot 1$ expression (Fig. 2). No expression of Uncx4.1 was observed in the adenohypophysis (Fig. 2).

\section{The hypothalamo-neurohypophysial system in Uncx4.1 mutant mice}

Uncx4·1-null mutant mice have been generated and display abnormal development of the caudolateral sclerotome (Leitges et al. 2000, Mansouri et al. 2000). Uncx $4 \cdot 1^{-/}$mice die at birth, probably due to respiratory failure. No obvious, gross abnormalities have been described in the central nervous system (Leitges et al. 2000, Mansouri et al. 2000). In this study we focused on the neuroendocrine hypothalamus and analysed vasopressin precursor neurons by in situ hybridization at E18.5, when the HNS has just been established (Ugrumov 2002). Vasopressin was expressed in the PVN and SON (Fig. 3A-D). No macroscopical differences between Unx4·1-null mutants and heterozygous littermates were observed. Furthermore, the expression of Otp in the mutant was normal (not shown). These results indicated that magnocellular neurons of the SON and PVN develop normally and express peptide hormone.

Next we analysed the HNS fibre system using an antiserum against the $\mathrm{C}$-terminal glycopeptide of the vasopressin precursor (van Leeuwen et al. 1989). The staining of the vasopressinergic cell bodies in the PVN, SON and the fibre systems of the pituitary stalk and median eminence were normal in appearance. Surprisingly, in multiple Unx4·1-null mutants an aberrant and intense staining was observed unilaterally in the adenohypophysis (Fig. 3E-J). The aberrant staining in the adenohypophysis did not originate from local synthesis, since no vasopressin mRNA was detected in the adenohypophysis (Fig. 3A-D). We noted that some homozygous mutants (three out of seven) did not display this ectopic C-terminal glycopeptide immunoreactivity in the adenohypophysis, suggesting that the phenotype is not fully penetrant.

Abnormal presence of vasopressin precursor product in the adenohypophysis, without mRNA, is suggestive of incorrect targeting of vasopressinergic axons. Therefore, we analysed Cresyl Violet-stained paraffin sections of embryonic brain and pituitary in closer detail (Fig. 4). These sections showed an abnormal structure connecting the neurohypophysis with the adenohypophysis in the Uncx4-1 mutant (Fig. 4A and B, just below the asterisk). This 'tissue bridge' of perfectly aligned cells, filled with material suggestive of fibre tracts, was never observed in wild-type animals. This dysmorphology was not fully penetrant $(50 \%)$ in all homozygous animals (four out of seven) and only occurred unlaterally. In one heterozygous animal, a partial 'tissue bridge' between neuro- and adenohypophysis was seen.
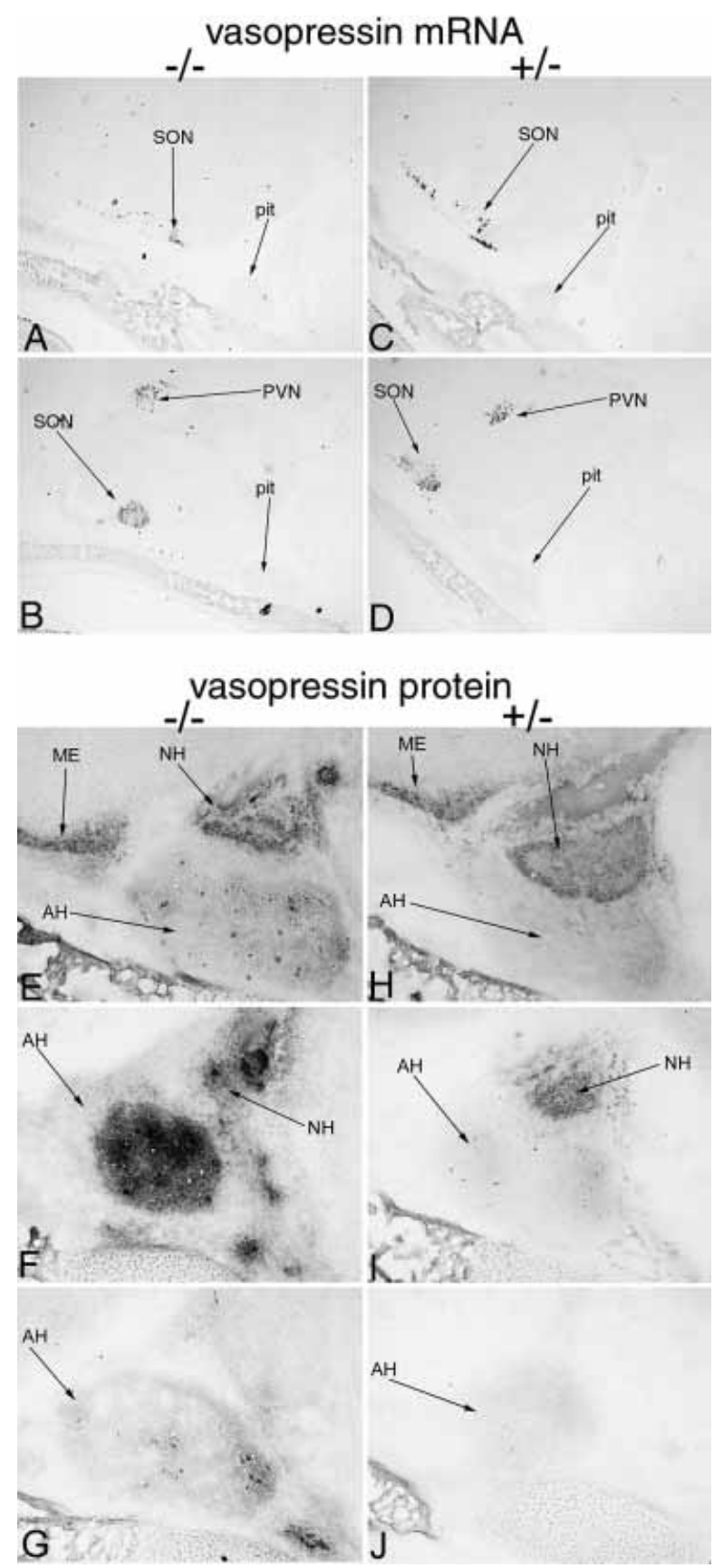

Figure 3 Analysis of expression of vasopressin mRNA and vasopressin precursor protein in the Uncx4-1-null mutant. Vasopressin mRNA was detected by in situ hybridization on sagittal sections of E18.5 mouse embryos (A-D). Expression in Uncx4.1 $1^{-/-}$and Uncx4.1+/- mice was similar, and limited to the PVN and SON (A-D). Vasopressin precursor protein was detected by $\mathrm{C}$-terminal glycopeptide immunoreactivity in the median eminence (ME) and neurohypophysis (NH) of Uncx $4 \cdot 1^{-/-}$and Uncx $4 \cdot 1^{+/-}$animals $(E, H)$. In more lateral sections through the adenohypophysis, ectopic C-terminal glycopeptide staining is present in Uncx $4 \cdot 1^{-1-}$ mice $(F, G)$, but not in heterozygous controls $(\mathrm{I}, \mathrm{J})$. $\mathrm{AH}$, adenohypophysis; pit, pituitary. 


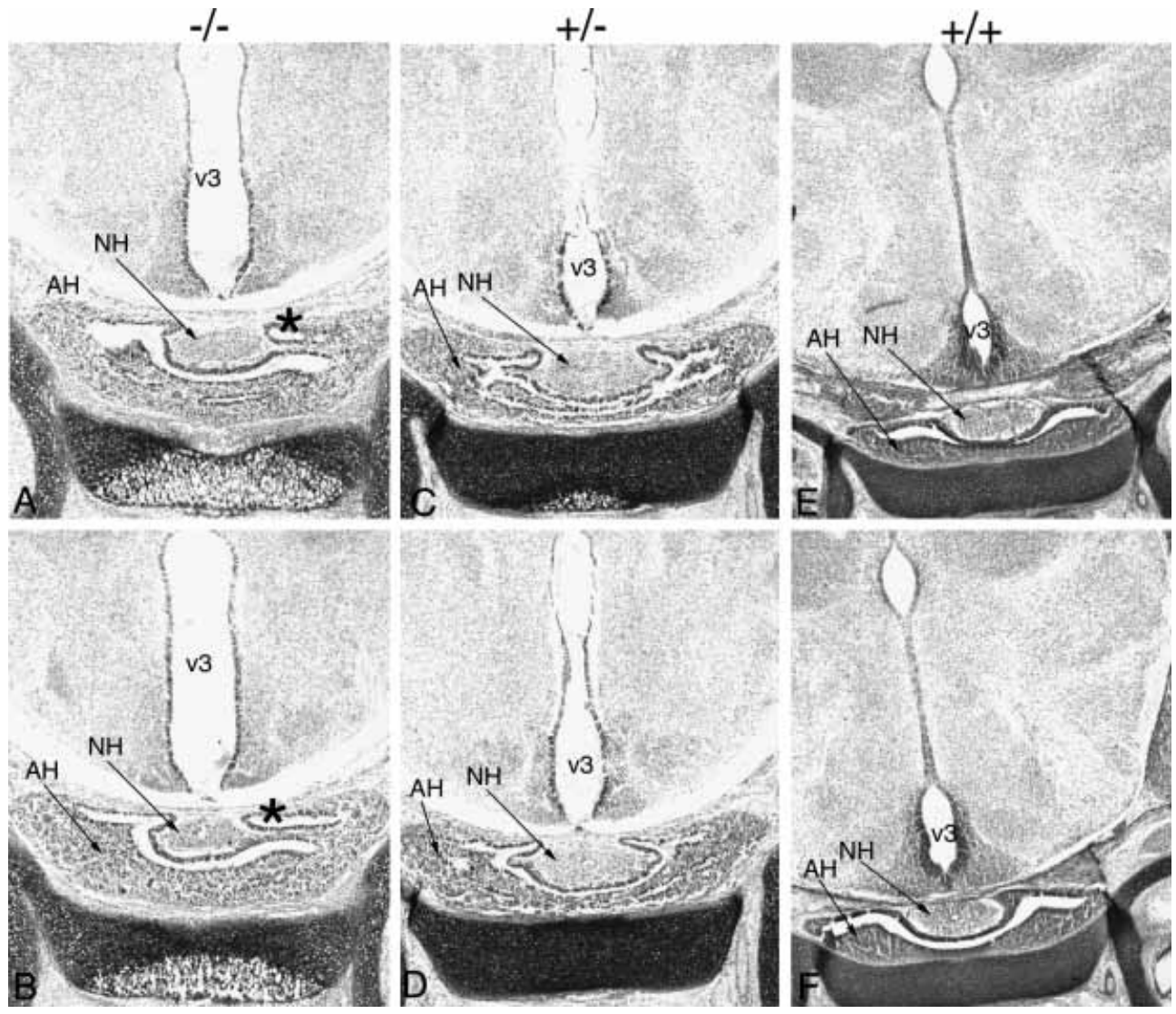

Figure 4 Presence of an abnormal connection between neurohypophysis $(\mathrm{NH})$ and adenohypophysis $(\mathrm{AH})$ in the Uncx4.1 mutant. Cresyl Violet coronal paraffin sections of E18.5 embryos show a 'tissue bridge' of perfectly aligned cells and fibrous tissue in Uncx $4 \cdot 1^{-1-}$ animals $(A, B)$ forming a connection between neurohypophysis and adenohypophysis. This dysmorphology is absent in heterozygous $(C, D)$ and wild-type control mice $(E, F)$. v3, third ventricle.

\section{Discussion}

In several structures of the nervous system, homeobox genes function as regulators of neuronal subtype specification during development (Jessell 2000). A specific feature of development of a neuronal lineage in which a homeobox gene is either removed by homologous recombination or ectopically expressed is the establishment of specific connectivity through appropriate pathfinding by axons extending from the cell bodies (Thor et al. 1999). An additional factor regulating axon guidance is the environment, and again homeobox genes serve an extraordinary role in patterning this environment to meet proper axonal responsiveness (Kania et al. 2000, Marin et al. 2002). A third cue for axonal projections is the target site. Molecular characteristics of the target can be regulated by homeobox genes, allowing correct axonal connections to be made and established. Unc-4 plays such a role in the nervous sytem of the nematode Caenorhabditis elegans. Inactivation of Unc-4 in C.elegans causes discon- nection of the normal target neurons and inappropriate connections to other neurons. It has been indicated that Unc-4 functions to invoke appropriate synaptic specificities (Miller et al. 1992, Miller \& Niemeyer 1995, White et al. 1992). The data presented in this study indicate that its murine orthologue Uncx $4 \cdot 1$ may have similar functions in the mammalian nervous system. The results suggest that this function is exerted by Uncx $4 \cdot 1$ in the development of the HNS.

Clearly, the phenotype of the Uncx $4 \cdot 1$ mutant that appears from this study is entirely different from those of other hypothalamic transcription factor mutants. In those mutants, phenotypes arise from early effects on terminal differentiation and/or survival of the entire population of neuroendocrine cells (Acampora et al. 1999, Michaud et al. 1998, 2000, Schonemann et al. 1995, Wang \& Lufkin 2000) before the formation of axonal projections to the neurohypophysis occur (Ugrumov 2002). We find that magnocellular peptidergic neurons are normally formed in Uncx $4 \cdot 1$ mutant 
mice, at positions similar to wild-type littermates. Since no gross abnormalities were found, and vasopressin expression was normal, Uncx $4 \cdot 1$ cannot be upstream of Otp, Siml/Arnt2 and Brn2 in the cascade of PVN and SON development. As expected, the regulatory gene Otp was normally expressed in the Uncx $4 \cdot 1$ mutant. The vasopressin gene was normally expressed in the hypothalamus, and vasopressin precursor products were present in the neurohypophysis. However, the phenotype consisted of ectopic localization of C-terminal glycopeptide-immunoreactivity in the adenohypophysis and the presence of a connection between the neural lobe and the anterior lobe of the pituitary gland. Since local ectopic vasopressin precursor transcripts were absent and cell nuclei were absent in these structures we interpret these morphological structures as extending vasopressinergic fibres entruding from the posterior lobe into the adenohypophysis.

These morphological abnormalities were observed in Uncx $4 \cdot 1$ mutants, but never in wild-type mice. This phenotype was not fully penetrant, since we did not detect vasopressin or the 'tissue bridge' in the anterior pituitary of all mutants. The expression of Uncx $4 \cdot 1$ in the adult and late-embryonic hypothalamus appears to be weak compared with Otp and Brn2, which could account for the partial penetrance.

A second influence on the penetrance of this phenotype is the genetic background of the mice. The Uncx $4 \cdot 1$ mice were kept on a mixed $129 \times$ NMRI background. Further breeding on other genetic backgrounds may reveal a more complete penetrance, since genetic modifiers of Uncx $4 \cdot 1$ function may exist. Partial penetrance of an axon pathfinding defect has also been observed for the LIM homeobox gene Lhx3. Null mutation or ectopic expression of Lhx3 enforces spinal-cord motor neurons to reorient their axonal projections (Sharma et al. 1998). The specific combination of expressed homeobox genes can convert axonal projections, and alternative targets can be reached when the occupancy of the new targets are elevated (Sharma et al. 2000). In the posterior pituitary, a default stop of axon growth may exist normally in wildtype animals. In null mutants this stop may be weakened due to the lack of specific molecular cues on the growing magnocellular fibres.

In C. elegans, the Unc-4 phenotype is fully penetrant. Ventral motor neurons of the A type (VA 2-12) take over part of the phenotype of their sister neurons of the B type (VB 3-11) and now receive synaptic input from interneurons that normally project to $\mathrm{VB}$ neurons (Miller et al. 1992, White et al. 1992, Miller \& Niemeyer 1995). VA motor neurons express Unc-4, and its co-repressor Unc-37, the homologue of Groucho (Miller \& Niemeyer 1995, Winnier et al. 1999). Together, these genes prevent expression of VB-specific genes in VA neurons (Winnier et al. 1999). Similarly, complementary expression of homeodomain genes vab-7 and unc-4 specifies differences between DA and DB motorneurons through inhibition of alternative fates (Esmaeili et al. 2002). It has been found that Unc-4-/Grouchodependent gene repression not only controls specificity of the synaptic input, but also the strength of synaptic outputs for all motor neurons in which unc-4 is expressed (Lickteig et al. 2001). While input is altered, axonal projections of VA motor neurons are normal in the unc-4 mutant. So, while the phenotype is consequently observed, the fate switch is partial. In fact, only those Unc-4-expressing neurons that have linear sisters undergo a fate switch towards these sister cells (Winnier et al. 1999). In mice, there is no obvious population of 'sister' cells to the supraoptic/ paraventricular area domain in the development of the SON and PVN. So, the fate switch of PVN and SON neurons may just be the de-repression of some, currently unknown genes. The resulting phenotype seems to be that axons from PVN and SON no longer halt at the proper position in the neurohypophysis, but instead grow into the adenohypophysis. These observations and the parallels to Unc-4-associated phenotypes in C. elegans may provide entries to developmental mechanisms required for the formation of the delicate architecture of the neurohypophysis which is unique in its humoral secretion of neural factors.

\section{Funding}

The research described in this paper has been funded by the Netherlands Organization for Scientific Research NWO, grant NWO-SLW 805-33.211-P. We declare that there is no conflict of interest that would prejudice its impartiality.

\section{Acknowledgement}

We are grateful to Dr Bert van der Zwaag for re-evaluation of Uncx $4 \cdot 1$ expression.

\section{References}

Acampora D, Postiglione MP, Avantaggiato V, Di Bonito M, Vaccarino FM, Michaud J \& Simeone A 1999 Progressive impairment of developing neuroendocrine cell lineages in the hypothalamus of mice lacking the Orthopedia gene. Genes \& Development 13 2787-2800.

Asbreuk CH, van Schaick HS, Cox JJ, Smidt MP \& Burbach JP 2002 Survey for paired-like homeodomain gene expression in the hypothalamus: restricted expression patterns of $\mathrm{Rx}, \mathrm{Alx} 4$ and goosecoid. Neuroscience $114883-889$.

Burbach JP, Luckman SM, Murphy D \& Gainer H 2001 Gene regulation in the magnocellular hypothalamo-neurohypophysial system. Physiological Reviews 81 1197-1267. 
Esmaeili B, Ross JM, Neades C, Miller III DM \& Ahringer J 2002 The $\mathrm{C}$ elegans even-skipped homologue, vab-7, specifies DB motoneurone identity and axon trajectory. Development 129 853-862.

Jessell TM 2000 Neuronal specification in the spinal cord: inductive signals and transcriptional codes. Nature Reviews Genetics 1 20-29.

Kania A, Johnson RL \& Jessell TM 2000 Coordinate roles for LIM homeobox genes in directing the dorsoventral trajectory of motor axons in the vertebrate limb. Cell 102 161-173.

Keith B, Adelman DM \& Simon MC 2001 Targeted mutation of the murine arylhydrocarbon receptor nuclear translocator 2 Arnt2 gene reveals partial redundancy with Arnt. PNAS 98 6692-6697.

Leitges M, Neidhardt L, Haenig B, Herrmann BG \& Kispert A 2000 The paired homeobox gene Uncx41 specifies pedicles, transverse processes and proximal ribs of the vertebral column. Development 127 2259-2267.

Lickteig KM, Duerr JS, Frisby DL, Hall DH, Rand JB \& Miller III DM 2001 Regulation of neurotransmitter vesicles by the homeodomain protein UNC- 4 and its transcriptional corepressor UNC-37/groucho in Caenorhabditis elegans cholinergic motor neurons. Fournal of Neuroscience 21 2001-2014.

Lin X, State MW, Vaccarino FM, Greally J, Hass M \& Leckman JF 1999 Identification, chromosomal assignment, and expression analysis of the human homeodomain-containing gene Orthopedia OTP. Genomics 60 96-104.

Mansouri A, Yokota Y, Wehr R, Copeland NG, Jenkins NA \& Gruss P 1997 Paired-related murine homeobox gene expressed in the developing sclerotome, kidney, and nervous system. Developmental Dynamics 210 53-65.

Mansouri A, Voss AK, Thomas T, Yokota Y \& Gruss P 2000 Uncx 41 is required for the formation of the pedicles and proximal ribs and acts upstream of Pax9. Development 127 2251-2258.

Marin O, Baker J, Puelles L \& Rubenstein JL 2002 Patterning of the basal telencephalon and hypothalamus is essential for guidance of cortical projections. Development 129 761-773.

Michaud JL, Rosenquist T, May NR \& Fan CM 1998 Development of neuroendocrine lineages requires the bHLH-PAS transcription factor SIM1. Genes \& Development 12 3264-3275.

Michaud JL, DeRossi C, May NR, Holdener BC \& Fan C 2000 ARNT2 acts as the dimerization partner of SIM1 for the development of the hypothalamus. Mechanisms of Development 90 253-261.

Miller III DM \& Niemeyer CJ 1995 Expression of the unc-4 homeoprotein in Caenorhabditis elegans motor neurons specifies presynaptic input. Development 121, 2877-2886.

Miller DM, Shen MM, Shamu CE, Burglin TR, Ruvkun G, Dubois ML, Ghee M \& Wilson L 1992 C elegans unc-4 gene encodes a homeodomain protein that determines the pattern of synaptic input to specific motor neurons. Nature 355 841-845.

Nakai S, Kawano H, Yudate T, Nishi M, Kuno J, Nagata A, Jishage K, Hamada H, Fujii H \& Kawamura K 1995 The POU domain transcription factor Brn-2 is required for the determination of specific neuronal lineages in the hypothalamus of the mouse. Genes \& Development 9 3109-3121.
Rovescalli AC, Asoh S \& Nirenberg M 1996 Cloning and characterization of four murine homeobox genes. PNAS 93 10691-10696 (Erratum. PNAS 199693 15522).

Schaeren-Wiemers N \& Gerfin-Moser A 1993 A single protocol to detect transcripts of various types and expression levels in neural tissue and cultured cells: in situ hybridization using digoxigenin-labelled cRNA probes. Histochemistry 100 431-440.

Schonemann MD, Ryan AK, McEvilly RJ, O'Connell SM, Arias CA, Kalla KA, Li P, Sawchenko PE \& Rosenfeld MG 1995 Development and survival of the endocrine hypothalamus and posterior pituitary gland requires the neuronal POU domain factor Brn-2 Genes \& Development 9 3122-3135.

Sharma K \& Peng CY 2001 Spinal motor circuits: merging development and function. Neuron 29 321-324.

Sharma K, Sheng HZ, Lettieri K, Li H, Karavanov A, Potter S, Westphal H \& Pfaff SL 1998 LIM homeodomain factors Lhx3 and Lhx4 assign subtype identities for motor neurons. Cell $\mathbf{9 5}$ 817-828.

Sharma K, Leonard AE, Lettieri K \& Pfaff SL 2000 Genetic and epigenetic mechanisms contribute to motor neuron pathfinding. Nature 406 515-519.

Smidt MP, Van Schaick HS, Lanctot C, Tremblay JJ, Cox JJ, Van der Kleijn AA, Wolterink G, Drouin J \& Burbach JPH 1997 A homeodomain gene Ptx3 has highly restricted brain expression in mesencephalic dopaminergic neurons. PNAS 94 13305-13310.

Thor S, Andersson SG, Tomlinson A \& Thomas JB 1999 A LIM-homeodomain combinatorial code for motor-neuron pathway selection Nature 397 76-80

Ugrumov MV 2002 Magnocellular vasopressin system in ontogenesis: development and regulation. Microscopy Research \& Technique 56 164-171.

van Leeuwen F, van der Beek E, Seger M, Burbach JP \& Ivell R 1989 Age-related development of a heterozygous phenotype in solitary neurons of the homozygous Brattleboro rat. PNAS 86 6417-6420.

van Schaick HS, Smidt MP, Rovescalli AC, Luijten M, van der Kleij AA, Asoh S, Kozak CA, Nirenberg M \& Burbach JP 1997 Homeobox gene Prx3 expression in rodent brain and extraneural tissues. PNAS 94 12993-12998.

Wang W \& Lufkin T 2000 The murine otp homeobox gene plays an essential role in the specification of neuronal cell lineages in the developing hypothalamus. Developmental Biology 227 432-449.

White JG, Southgate E \& Thomson JN 1992 Mutations in the Caenorhabditis elegans unc-4 gene alter the synaptic input to ventral cord motor neurons. Nature 355 838-841.

Winnier AR, Meir JY, Ross JM, Tavernarakis, N, Driscoll M, Ishihara T, Katsura I \& Miller III DM 1999 UNC-4/UNG-37-dependent repression of motor neuron-specific genes controls synaptic choice in Caenorhabditis elegans. Genes $\mathbb{E}$ Development $132774-2786$.

Received 16 August 2005 Accepted 10 October 2005 